\title{
MORPHOLOGICAL RESPONSE TO THE DEEP WATERWAY PROJECT AROUND THE CHANGJIANG ESTUARY, CHINA
}

\author{
Lingzhi Pan, Pingxing Ding, Jianzhong Ge
}

\section{INTRODUCTION}

The Changjiang Estuary is characterized by complex branches and outlets (North Branch, North Channel, North Passage and South Passage). The relatively shallow bathymetry around the mouth limits the navigational potentials (Fig.1). The Deep Waterway Project (DWP) was carried out in the North Passage of South Channel for the purpose of deepening the navigational channel from $7.0 \mathrm{~m}$ in July 1998 to $8.5 \mathrm{~m}$ in July 2001 (Phase I), $10.0 \mathrm{~m}$ in May 2005 (Phase II) and $12.5 \mathrm{~m}$ in May 2010 (Liu et al. 2004 and 2009). In addition to dredging, two dykes were constructed to reduce the sediment transport from Jiuduansha and Hengsha Shoals into North Passage. A set of groins was built with connection to dykes for the purpose of strengthening the currents in the middle of channel, which helps the maintenance of the navigational capability.

The construction has significantly changed the local bathymetry in the Changiiang Estuary and within the channel. The high-resolution bathymetry measurements were made over seasons. An evolution trend of the morphological change is revealed, which is discussed in this paper.
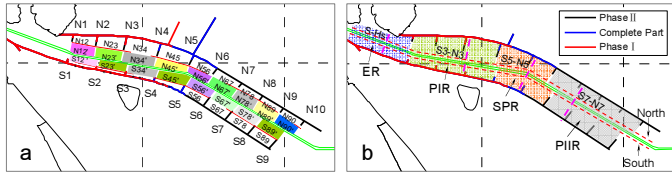

Fig. I Regions and transects in North Passage

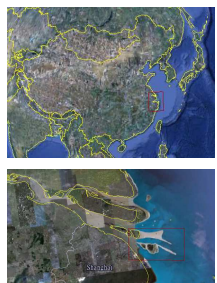

\section{DATA AND METHODS}

The measurements were made over the channel (North Passage) and its adjacent regions, with the horizontal resolution of $\sim 50-100 \mathrm{~m}$ in the cross-channel direction and $1 \mathrm{~km}$ in the along-channel direction. The duration of the measurement covered the period from March 2000 to May 2008. To examine the spatial distribution of the morphological change, we have gridded the measurement area with different size boxes (Fig.1). An analysis is focused on boxes, which are labelled N12 and S12 et. Near groin-dykes, N12' and S12 ' et. Near the shoal, ER at the entrance, PIR at the Phase I Region, SPR at the area after PIR, PIIR at the Phase II Region. The transitions between these regions are also examined(Fig.2b).

\section{RESULTS AND DISCUSSION}

Our analysis shows the morphology over the study area has been significantly changed after DWP. Major characteristics of the erosion and deposition are summarized as follows

\section{1) After the Phase I of the project was} completed, the box named PIR was eroded significantly as a result of the reciprocating flow produced by the dykes' blocking. The erosion thickness was about $2 \mathrm{~m}$. The area near groins, however, was featured with an increase of deposition as a result of weakening the flow around groins and dykes. The deposition thickness can be up to about $4 \mathrm{~m}$ in N45' (Fig.2a). In spite of deposition around groynes, the project did meet the goal to deepen the navigation channel to $8 \mathrm{~m}$.

2) The supplement construction for the Phase I of the project was conducted to extend the northern dyke seaward and to block the East Hengsha Passage. After this construction was completed, N45' turned

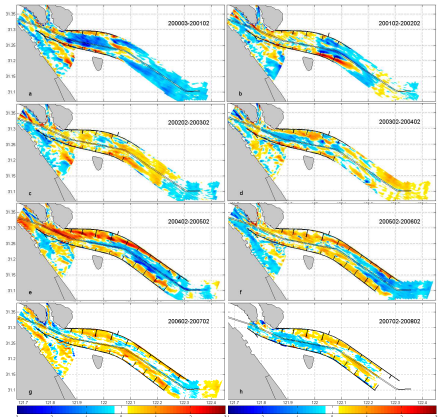

Fig. 2 Morphological changes in every year to an erosion area (Fig.2b)

3) Corresponding to the Phase II of the project, both deposition area near groins and erosion area near the shoal shifted seaward. The area around groins in PIR was deposited significantly after the northern groins of Phase I of the project was prolonged (Fig.2d-f).
4) Near groines and dykes, the deposition thickness was increased during first two years after the groines were instakked, but it decreases rapidly at a decline rate of $30 \sim 60 \%$ per year.

5) The total volume of the deposition sediment was about $0.64 \times 10^{8} \mathrm{~m}^{3}$ in ER-an area in which the deposition thickness was up to $7 \mathrm{~m}, 3.67 \times 10^{8} \mathrm{~m}^{3}$ near-groins-an area in which the deposition thickness was up to $4 \sim 5 \mathrm{~m},-0.72 \times 10^{8} \mathrm{~m}^{3}$ near-shoal-an area in which the erosion thickness was up to 3 4 m from January 1998 to May 2008 (Fig.3-4)

6) The morphological change varies with seasons. The area of near-shoal was deposited in the flood season and eroded in the dry season, while the area of near-groins was deposited more significantly in the flood season than in the dry season.
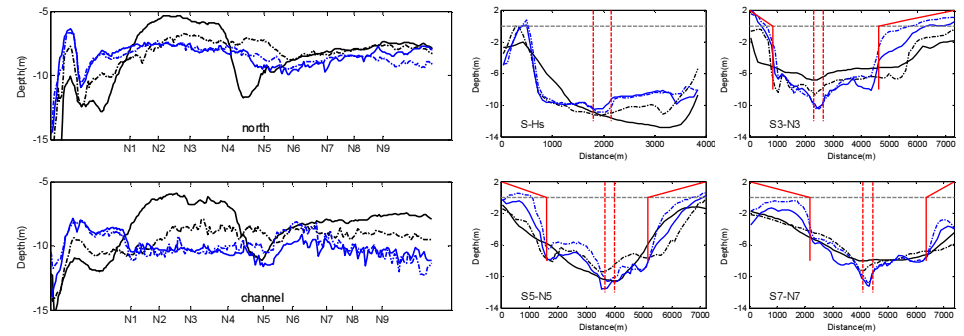

Red solid: groins; Red dashed: channel
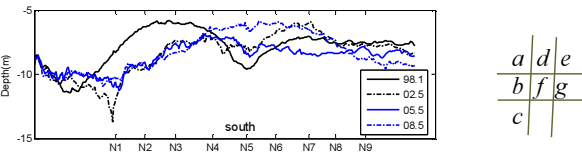

Fig. 3 The different depth in different time at transects
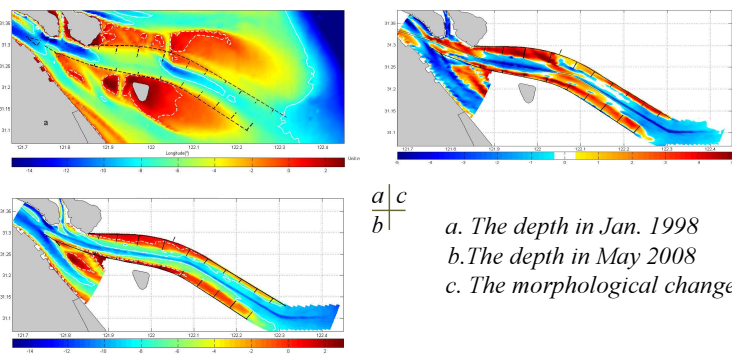

$\frac{a \mid c}{b} \quad$ a. The depth in Jan. 1998

b. The depth in May 2008

c. The morphological change

Fig. 4 The depthes and morphological change

\section{CONCLUSIONS AND FUTURE PLAN}

The morphological evolution over the Deep Waterway varied in space and time. This feature calls an additional dynamical mechanism study. The Delft3D is configured for this purpose.

\section{References}

Liu Jie, Xu Zhiyang, Zhao Dezhao. Change of Re-siltation in the Yangtze Estuary Deepwater Channel during Ist and 2nd Stages, Journal of Sediment Research. No.2, Apr.2009.

Liu Jie, Chen Jiyu, Le Jiahai. Erosion-deposition Analyses on the North Passage after Implementing the First Stage Project of the Yangtze Estuary Deepwater Channel Regulation, Journal of Sediment Research. No.5, Oct.2004.

\section{Contact Information}

Lingzhi Pan, East China Normal University

E-mail: lzpan_shanghai@yahoo.com.cn Phone : 85-021-62232495

Pingxing Ding, East China Normal University E-mail: pxding@sklec.ecnu.edu.cn

Jianzhong Ge, East China Normal University E-mail: gegsdw@hotmail.com 